\title{
An efficient low-speed airfoil design optimization process using multi-fidelity analysis for UAV flying wing
}

- Anh Bao DINH ${ }^{1}$

- Khanh Hieu NGO ${ }^{1}$

- Nhu Van NGUYEN ${ }^{2}$

${ }^{1}$ Ho Chi Minh City University of Technology, VNU-HCM

${ }^{2}$ Konkuk University, South Korea

(Manuscript Received on March 22nd, 2016, Manuscript Revised May 30th, 2016)

\begin{abstract}
This paper proposes an efficient lowIt has low parasite drag, long endurance, and speed airfoil selection and design optimization process using multi-fidelity analysis for a long endurance Unmanned Aerial Vehicle (UAV) flying wing. The developed process includes the low speed airfoil database construction, airfoil selection and design optimization steps based on the given design requirements. The multi-fidelity analysis solvers including the panel method and computational fluid dynamics (CFD) are presented to analyze the low speed airfoil aerodynamic characteristics accurately and perform inverse airfoil design optimization effectively without any noticeable turnaround time in the early aircraft design stage. The unconventional flying wing UAV design shows better performance. The multi-fidelity analysis solvers are validated for the E387 and CAL2463m airfoil compared to the wind tunnel test data. Then, 29 low speed airfoils for flying wing UAV are constructed by using the multifidelity solvers. The weighting score method is used to select the appropriate airfoil for the given design requirements. The selected airfoil is used as a baseline for the inverse airfoil design optimization step to refine and obtain the optimal airfoil configuration. The implementation of proposed method is applied for the real flyingwing UAV airfoil design case to demonstrate the effectiveness and feasibility of the proposed method.
\end{abstract} poor reaction in longitudinal stability. However,

Key words: Low-speed airfoil, airfoil optimization, multi-fidelity analysis, flying wing UAV

\section{INTRODUCTION}

Airfoil plays an extremely important role for the aircraft aerodynamics, performance, and stability. Therefore, the airfoil selection process is very essential and significant at the early aircraft design stage to support designers for selecting an appropriate airfoil with the given 
requirements. The basic airfoil aerodynamic characteristics include airfoil lift, drag, and pitching moment coefficient that are required to evaluate by performing the test at the specific working condition of the airfoil. For example, many airfoil aerodynamics data were tested at the $2.8 \times 4.0 \mathrm{ft}(0.853 \times 1.219 \mathrm{~m})$ low-turbulence wind tunnel in the Subsonic Aerodynamics Research Laboratory at the University of Illinois at Urbana-Champaign (UIUC) [1]. However, doing such a test could be time-consuming and costly. Moreover, errors could be made because the working condition of the selected airfoils is not always the same as the testing data as the result of approximation [1]. Hence, many researchers currently implement the reliable and accurate prediction analysis tools such as panel method, Reynolds-averaged Navier-Stokes (RANS), and in-house CFD solvers to analyze and design airfoil. However, these different analysis methods are required for the different flow conditions. In this paper, the flight regime is the low-speed which means the flow through the airfoil includes three regions: laminar, turbulent and transition zone. Besides, the high-fidelity analysis contains fully turbulent problem. Thus, the drag coefficient is higher than experiment results at the low speed regime. Meanwhile, results of low-fidelity analysis in less accurate for terms of the lift but pretty good about drag issues [2]. P. D. Silisteanu et al. introduced a method for estimating the transition onset and extension based on the temporal parameter of the skin friction coefficient and flow vorticity at the wall [2]. This method shows that the relative error in the drag coefficient is lower than $8 \%$ when a fully turbulent model can introduce error up to $50 \%$. R. B. Langtry et al. used the $\gamma-\overline{R e_{\theta t}}$ model for low-speed [3]. This model requires the solution based on two transport equations, one for intermittency and one for a transition onset criterion in terms of momentum thickness Reynolds number. Since its development, the $\gamma-\overline{R e_{\theta t}}$ model has been adapted by $A$. $C$. Aranake et al. [4] for use with the SpalartAllmaras turbulent model [5] and $k-\omega$ turbulent model [6]. The Spalart-Allmaras model is more widely used application for aerospace applications involving wall-bounded flows, and it is also typically less expensive, resolves one transition equation. However, in order to perform these methods, the knowledge of Computational Fluid Dynamics (CFD) is required. The panel method is used via XFLR5 code [18]. Mark Drela [7] used an inverse method incorporated in Xfoil based on surface speed distribution of airfoil baseline. There are two types of this method: full inverse and mixed inverse. It calculates the entire airfoil. Similarly, T. $R$. Barrett et al. [8] used the inverse method by RANS solver as a high-fidelity analysis. However, these methods have difficulties for modifying the surface speed distribution. Hence, some methods are developed to airfoil shape parameterization. One of the most popular method for airfoil representation is the Bézier curve, which introduces control point around the geometry. These points are used to define the airfoil shape. N. V. Nguyen et al. [9] modeled airfoil geometry by the class shape function transformations (CST) method [10]. CST method is defined by combined class function with shape function. Ma Dongli et al. [11], Ava Shahrokhi et al. [12] and Slawomir Koziela et al. [13] used airfoil NACA function instead of airfoil basline.

Besides, in this case-study, cruise speed is $20 \mathrm{~m} / \mathrm{s}$, the Mach number is 0.06 . Therefore, this paper proposed the efficient airfoil selection and

\section{Trang 44}


design optimization process that uses the multifidelity including panel method and CFD solvers. The flying wing UAV is well-known for high performance due to the low parasite drag with the same engine power.

\section{EFFICIENT LOW-AIRFOIL DESIGN OPTIMIZATION PROCESS}

The overall process of efficient low-speed airfoil design optimization is presented in F. 1. It includes three-steps that are UAV airfoil database construction loop, airfoil section loop, and airfoil design optimization loop. The framework starts with UAV airfoil database construction loop. The fully airfoil database is generated based on requirements and executed by the multi-fidelity analysis. In the airfoil section loop, from the fully airfoil database, Weighted Scoring Method (WSM) is employed for finding maximum weight value by criteria for the UAV flying wing. Then, airfoil selected is sent to airfoil design optimization loop. Then, this airfoil is used for baseline airfoil in order to design optimal airfoil.

\subsection{UAV airfoil database construction loop}

The design of an aircraft or UAV generally begins with identifying requirements, i.e. endurance, stall speed, cruise speed in UAV airfoil database construction loop. Then, finding suitable Airfoils by using requirements. Airfoils in the collection are sent to the multi-fidelity analysis, to analysis aerodynamic characteristics of airfoil. Then, the results are collected in a fully airfoil database.

In this loop, the most important step is Multi-Fidelity Analysis. The multi-fidelity analysis includes the panel method and Reynolds-averaged Navier-Stokes (RANS) solver by XFOIL and ANSYS FLUENT.

XFOIL [7] is probably the best known of the above codes. It dates back to 1986 and was written by Dr. Mark Drela, an aerodynamics professor at Massachusetts Institute of Technology. It is the coupled panel method with an integral boundary layer calculation for analysis [14].

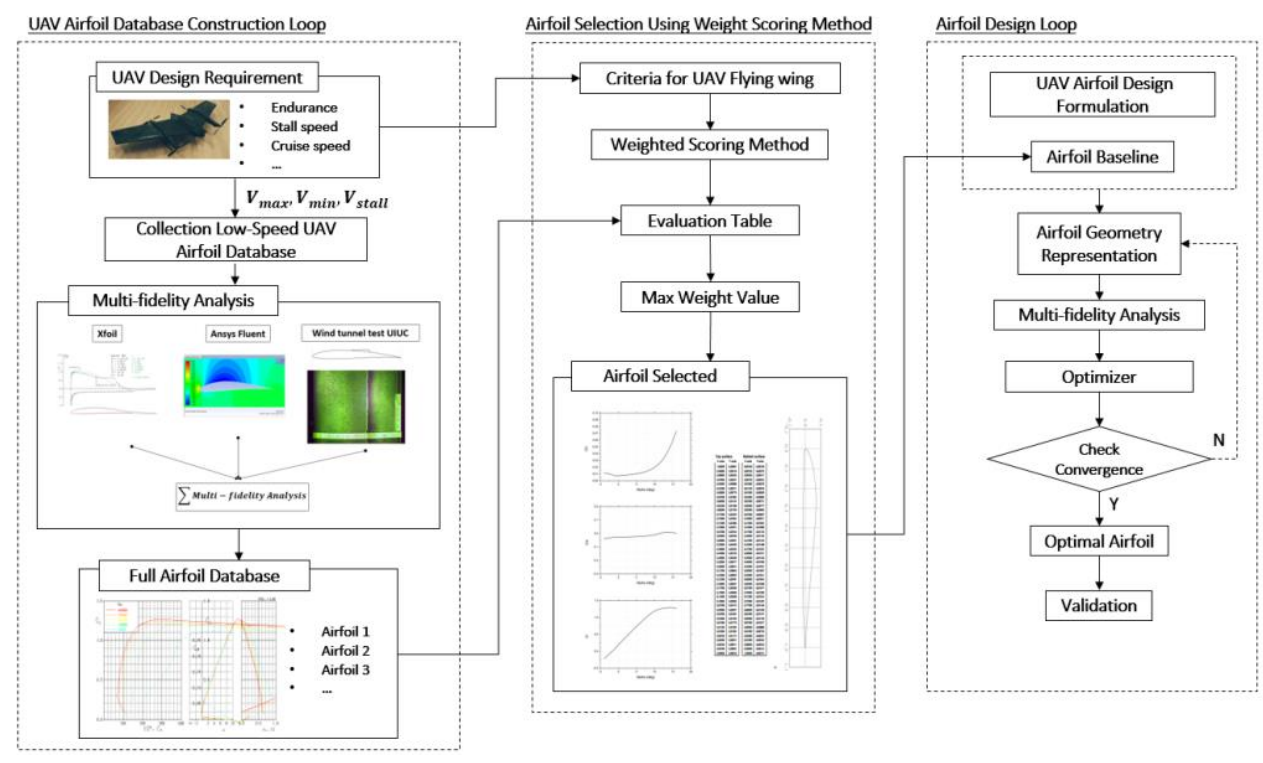

Figure 1. Efficient Low-Speed Airfoil Design Optimization 
ANSYS FLUENT [17] is a Navier-Stokes solver that can operate in either two-dimensional or three-dimensional models, solvers are based on the finite volume method (FVM). Besides, CFD needs fine grid generation, and the structured grid is more preferable than unstructured grid since it can avoid the divergence caused by rough grid. The user is allowed a wide selection of turbulence models. In this paper, low Reynolds number flow mechanism is expounded by the numerical simulation of several airfoils using Reynoldsaveraged Navier-Stokes (RANS) equations. "Steady" and "pressure-based" are used.

\subsection{Airfoil section loop}

Identify criteria for UAV flying wing by using requirement of Airfoil Database Loop. Weighted Scoring Method (WSM) is employed for finding maximum weight value from the Fully Airfoil Database. The airfoil has maximum score is found.

Criteria for UAV Flying wing: From UAV design requirement, the criteria for the best performance have to be set in order to select the proper airfoil.

Weighted Scoring Method (WSM): is a selection method comparing multi criteria. It includes determination of all the criteria related to the selection which gives each criteria a weighted score to reflect their relative importance and evaluation of each criteria. WSM consists of these following steps:

+ Determining all the criteria.

+ Creating evaluation table for each airfoil bases on criteria.

+ Making sum of all the products and selecting the airfoil with the highest total points from the full airfoil database.

\subsection{Airfoil design optimization loop}

Design formulation: Flying wing configuration operates with speed higher than fixed wing, so it has the low parasite drag, but stability issues inherent in this type of configuration. Thus, the improvement of pitching coefficient in cruise conditions is selected as an objective function for the current UAV airfoil design. The aerodynamic constraints are maximum lift coefficient, stall angle of attack, minimum drag coefficient and the coordinates of airfoil selected are used as design variables.

Airfoil geometry representation: Airfoil geometry is modeled as a projective Bézier curve. The general form of the mathematical expression is shown in Eq. 1. The Bézier curve is a weighted sum of the control points, $a_{i}$. By changing "control points" of Bézier curve of airfoil selected baseline, new airfoil coordinates are created (as shown in F. 2, F. 3).

$\left\{\begin{array}{c}\mathcal{B}(u)=\sum_{i=0}^{n} a_{i} b_{i, n}(u) \\ b_{i, n}(u)=\left(\begin{array}{c}n \\ i\end{array}\right) u^{i}(1-u)^{n-i}\end{array}\right.$ where $\mathcal{B}(u)=\frac{y}{c}, ; u=\frac{x}{c} ;\left(\begin{array}{l}n \\ i\end{array}\right)=\frac{n !}{i !(n-i) !}$

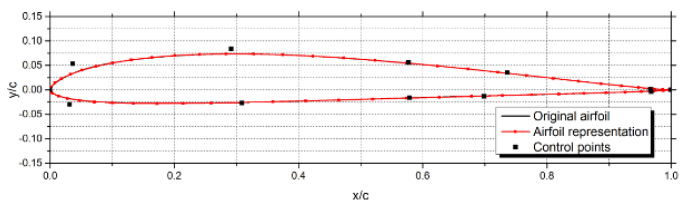

Figure 2. Airfoil representation

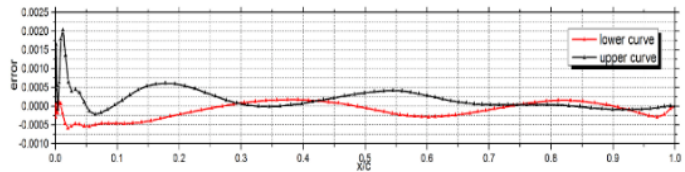

Figure 3. Error upper and lower curve 
Optimizer: Airfoil geometry representation is sent to multi-fidelity analysis. If the convergence is not satisfied, airfoil geometry representation is updated by changing control point.

\section{MULTI-FIDELITY SOLVER VALIDATION}

ANALYSIS

The E387 airfoil was designed by Richard Eppler in the mid-1960s for use in model sailplanes. Because it was designed specifically for the appropriate lift coefficients and Reynolds numbers required by its application, this airfoil became a touchstone for much of the research directed at increasing the understanding of low Reynolds number airfoil aerodynamics.

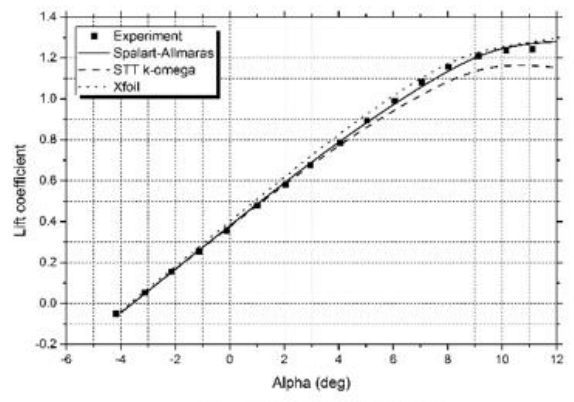

a) Lift coefficient
The aerodynamic characteristics predicted for $\mathrm{Re}=300000$ by XFOIL and FLUENT are compared to the UIUC wind-tunnel measurements [15]. A C-type grid with 33450 nodes, 33004 cells, 66454 faces and $\mathrm{y}_{\text {wall }}+=1.0$ is generated for the ANSYS FLUENT using the Pointwise tool [16].

In F. 4, these results are compared with those from the UIUC wind-tunnel for Re 300000. As seen from F. 4.a, these analytical tools have high-fidelity, Spalart-Allmaras turbulence models matches with experiment. This case study is the low Mach number, which exists both laminar and turbulent flow.

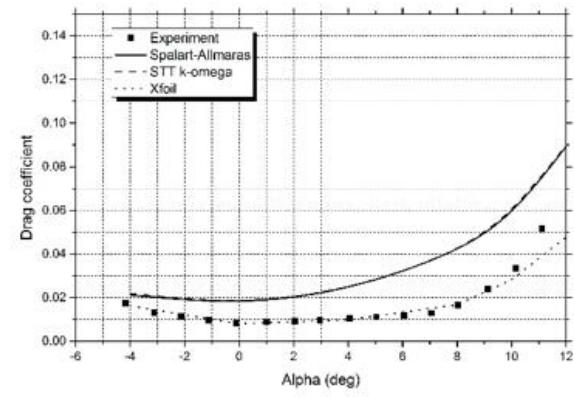

b) Drag coefficient

Figure 4. Comparison of predicted and measured aerodynamic characteristics for E 387 airfoil, Re $=300000$

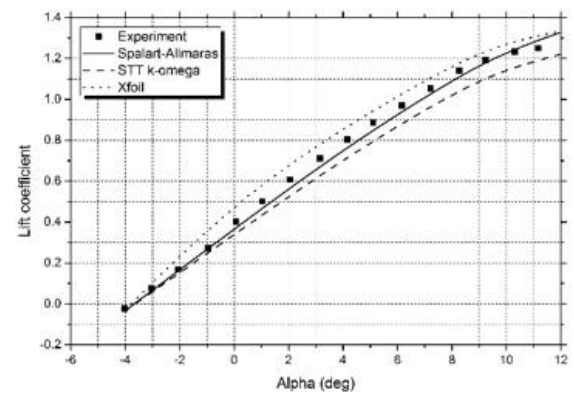

a) Lift coefficient

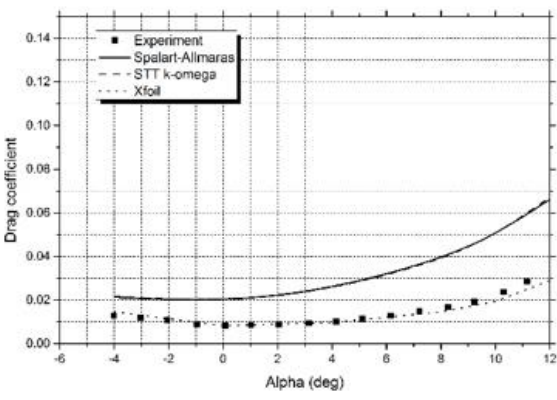

b) Drag coefficient

Figure 5. Comparison of predicted and measured aerodynamic characteristics for CAL $2463 \mathrm{~m}$ airfoil, $\operatorname{Re}=300000$ 
XFOIL used boundary layer equation and transition equation. In the FLUENT tool, the turbulence models used in the fully turbulent so drag coefficient is higher than XFOIL. Besides, results of multi-fidelity analysis of CAL2463m airfoil are the same, as shown in F. 5. So, SpalartAllmaras turbulence model is used for lift coefficient and XFOIL for the drag coefficient.

\section{CASE STUDY: UAV FLYING WING AIRFOIL DESIGN OPTIMIZATION}

\subsection{UAV Airfoil Database Construction Loop}

From the results of initial sizing, Reynolds number equals 300000 for case study.

Then, 29 airfoils are used for selection, as shown in Table 1.

Table 1. Collection Low-speed UAV flying wing Airfoil database

\begin{tabular}{llllll}
\hline No. & Airfoil & No. & Airfoil & No. & Airfoil \\
\hline 1 & E182 & 11 & MH 60-12\% & 21 & HS 130 \\
2 & E184 & 12 & TL 54 & 22 & S 5.0/1.0 \\
3 & E186 & 13 & TL 55 & 23 & S 5.0/2.0 \\
4 & EH 1.0/9.0 & 14 & TL 56 & 24 & SD 7003 \\
5 & EH 2.0/10 & 15 & HS 3.0/8.0B & 25 & SIPKILL \\
& & & & & $1.7 / 10 B$ \\
6 & EH 2.5/10 & 16 & HS 3.4/12B & 26 & JWL-065 \\
7 & EH 3.0/12 & 17 & HS 3.0/9.0B & 27 & EMX-07 \\
8 & MH 32 & 18 & HS 2.0/8.0 & 28 & RS 400A \\
9 & MH 45 & 19 & HS 520 & 29 & PHÖNIX \\
10 & MH 60 & 20 & HS 522 & & \\
\hline
\end{tabular}

\subsection{UAV Airfoil Database Construction Loop}

UAV flying wing has low parasite drag and poor stability, so criteria of stability is important, as shown in Table 2.

Table 2. Criteria for case study

\begin{tabular}{cll}
\hline No. & \multicolumn{1}{c}{ Coefficient } & Criteria \\
\hline 1 & $C_{l 0}$ & $10 \%$ \\
2 & $C_{m 0}$ at 0 deg & $5 \%$ \\
3 & $C_{m}$ at 2 deg & $15 \%$ \\
4 & $C_{\text {lmax }}$ & $20 \%$ \\
5 & $\alpha_{\text {stall }}$ & $15 \%$ \\
6 & $C_{d \min }$ & $15 \%$ \\
7 & $C_{l} / C_{d} \max$ & $10 \%$ \\
8 & $C l^{1.5} / C_{d} \max$ & $10 \%$ \\
\hline
\end{tabular}

Using WSM and Criteria in Table 2 for airfoil database to find airfoil has maximum weight value.

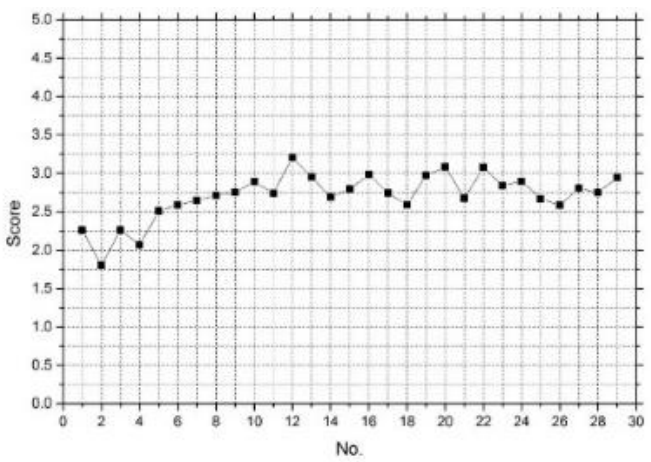

Figure 6. Score of Airfoil database

As shown in F. 6, the airfoil TL 54 (No.12) has maximum weight score, so airfoil baseline is TL54.

\subsection{Airfoil Design Optimization Loop}

As discussed above, the 2D airfoil design problem is based on TL54. Thus, the standard optimization problem is written as:

$$
\text { Maximize: } f(\bar{x})=C_{m 0}
$$

subject to:

$$
\left\{\begin{array}{l}
C_{L \max } \geq C_{\text {Lmax }_{T L 54}} \\
\alpha_{\text {stall }} \geq \alpha_{\text {stall }_{T L 54}} \\
C_{d \min } \leq C_{d_{\text {min }}}{ }_{T 54}
\end{array}\right.
$$

The optimal airfoil is shown in Table 3. The pitching moment coefficient of optimal airfoil increases $42.92 \%$ compared with the baseline airfoil TL 54. The maximum lift coefficient, stall angle of attack and minimum drag coefficient constraints are satisfying.

Table 3. Optimal Airfoil comparison

\begin{tabular}{cllll}
\hline & & Baseline (TL54) & Optimal airfoil & Unit \\
\cline { 1 - 4 } Objective & $C_{m 0}$ & -0.0049867 & -0.0028462 & - \\
\cline { 1 - 3 } Constraints & $C_{\text {Lmax }}$ & 1.2702 & 1.278 & - \\
& $\alpha_{\text {stall }}$ & 14 & 14 & deg \\
& $C_{\text {dmin }}$ & 0.0740 & 0.0736 & - \\
\hline
\end{tabular}




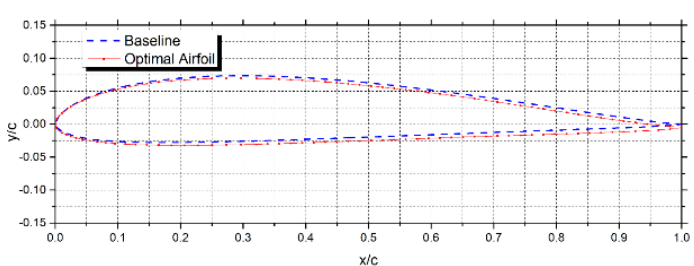

Figure 7. Baseline and optimal airfoil shape

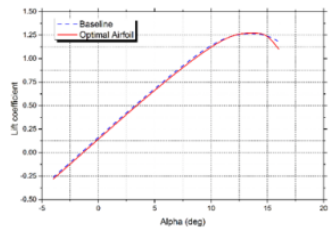

a) Lift coefficient

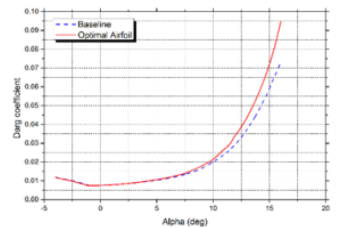

b) Drag coefficient

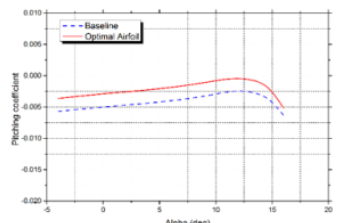

c) Pitching moment coefficien

Figure 8. Baseline and optimal airfoil polar comparison

Small differences in the stall angle of attack, the maximum lift coefficient and the minimum drag coefficient, as shown in Table 3 and F. 8. Because the pitching moment coefficient of optimal airfoil is so good, that increases stability of UAV flying wing. Besides, the pressure distribution of the airfoil for both optimal and baseline shows similar, as shown in F. 9.
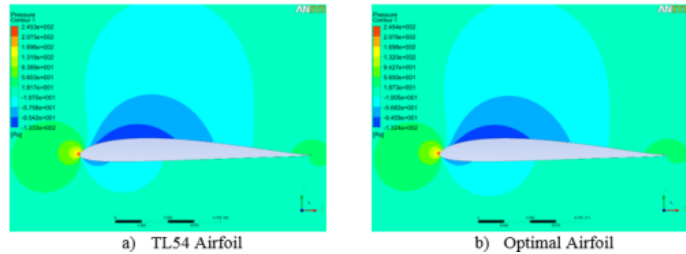

Figure 9. Optimal airfoil pressure distribution at $\mathrm{AOA}=0 \mathrm{deg}$

\section{CONCLUSIONS}

An airfoil design optimization for airfoil TL54 is developed and applied successfully for improving the stability with a trustworthy optimum configuration providing an improvement $42.92 \%$ in reliability.

By using Multi-fidelity analysis for airfoil selection, designers don't have to spend time, for testing data on airfoils from the wind tunnel, but still getting results close to the experiment. This is a promising approach since its accuracy and feasibility are demonstrated with the help of a case study. 


\section{Quy trình thiết kế tối ưu cho biên dạng cánh vận tốc thấp sử dụng phân tích đa độ tin cậy cho thiết bị bay không người lái dạng cánh \\ bay}

- Đinh Anh Bảo ${ }^{1}$

- Ngô Khánh Hiếu ${ }^{1}$

- Nguyễn Như Văn ${ }^{2}$

${ }^{1}$ Trường Đại học Bách khoa, Đại học Quốc gia Tp. Hồ Chí Minh

${ }^{2}$ Trường Đại học Konkuk, Hàn Quốc

\section{TÓM TẮT:}

Bài báo này đề xuất một quy trình lụa chọn và thiết kế tối uu airfoil vận tốc thấp bằng cách sử dụng phân tích đa độ tin câyy cho dòng máy bay không ngườ lái dạng cánh báy có thời gian bay dài. Quá trình phát triển bao gồm các buớc: xây dưng cơ sơ dũ liệu airfoil vận tốc thấp, lụa chọn airfoil và thiết kế tối un airfoil tù các yều cầu. Thuật toán phân tích đa độ tin cậy bao gồm phuoong pháp tấm và động lực học chất lỏng được giới thiệu để phân tích các đặc điểm khi động học của airfoil vận tốc thấp một cách chinh xác và sử dụng trong quy trình thiết kế tối uu hóa airfoil một cách hiệu quả mà không cần tốn nhiều thời gian trong giai đoạn đầu của thiết kế máy bay. UAV flying wing cho thấy phản ứng kém đối với ổn định theo chiều dọc. Tuy nhiên, nó có lục

Tù khóa: airfoil vận tốc thấp, phân tích airfoil, phân tích đa độ tin cậy, flying wing UAV cản thấp, thời gian hoạt động dài và hiệu suất tốt hơn. Thuật toán phân tích đa độ tin cậy được kiểm chứng bằng airfoil E387 và CAL2463m so với dũ liệu thử nghiệm trong hầm gió. Sau đó, dĩ liệu 29 airfoils vận tốc thấp của dòng UAV flying wing được xây dưng bằng cách sủ dụng giải thuật đa độ tin câyy. Phuoong pháp trọng số được sư dụng để chọn ra airfoil phù hợp với yêu cầu thiết kế nhất. Airfoil được chon được sủ dụng làm airfoil co sở cho buớc thiết kế tối uu hóa và có đuợc cấu hình airfoil tối uu. Quy trình đề xuất trên được thưc hiện cho một thiết kết thực máy bay không nguời lái dạng cánh bay để chưng minh tính hiệu quả và tính khả thi của phuong pháp.

\section{REFERENCES}

[1]. Michael S. Selig, Robert W. Deters, and Gregory A. Williamson, Wind Tunnel Testing 
Airfoils at Low Reynolds Numbers, 49 ${ }^{\text {th }}$ AIAA Aerospace Sciences Meeting, Orlando, Florida, Jan. 2011.

[2]. Paul-Dan Silisteanu, Ruxandra M. Botez, Transition Flow Occurrence Estimation New Method, $48^{\text {th }}$ AIAA Aerospace Sciences Meeting Including the New Horizons Forum and Aerospace Exposition, Orlando, Florida, Jan. 2010.

[3]. R. B. Langtry, J. Gola, and F. R. Menter, Predicting 2D Airfoil and $3 D$ Wind Turbine Rotor Performance using a Transition Model for General CFD Codes, 44 ${ }^{\text {th }}$ AIAA Aerospace Sciences Meeting and Exhibit, Reno, Nevada, Jan. 2006.

[4]. Aniket C. Aranake, Vinod K. Lakshminarayan, Karthik Duraisamy, Assessment of Transition Model and CFD Methodology for Wind Turbine Flows, 42 ${ }^{\text {nd }}$ AIAA Fluid Dynamics Conference and Exhibit, New Orleans, Louisiana, June 2012.

[5]. P. R. Spalart and S. R. Allmaras, A Oneequation Turbulence Model for Aerodynamic Flows, AIAA Paper 1992-0439, 30 ${ }^{\text {th }}$ AIAA Aerospace Sciences Meeting and Exhibit, Reno, Nevada, Jan. 1992.

[6]. F. R. Menter, Two-Equation EddyViscosity Turbulence Models for Engineering Application, AIAA Journal, vol. 32, no. 8, pp. 1598-1605, 1994.

[7]. M. Drela, XFOIL: An analysis and design system for low Reynolds number airfoils. In T.J. Mueller, editor, Low Reynolds Number Aerodynamics. Springer-Verlag, Jun 1989. Lecture Notes in Engineering, no. 54, http://web.mit.edu/drela/Public/web/xfoil.
[8]. Thomas R. Barrett, Neil W. Bressloff and Andy J. Keane, Airfoil Design and Optimization Using Multi-Fidelity Analysis and Embedded Inverse Design, $47^{\text {th }}$ AIAA/ASME/ASCE/AHS/ASC/ Structures, Structural Dynamics, and Materials Conference, Newport, Rhode Island, May 2006.

[9]. Nhu Van Nguyen, Maxim Tyan, JaeWoo Lee, Repetitively Enhanced Neural Networks Method for Complex Engineering Design Optimization Problems, Optimization and Engineering International Multidisciplinary Journal to Promote Optimization Theory \& Applications in Engineering Sciences, ISSN 1389-4420.

[10]. B. M. Kulfan, A Universal Parametric Geometry Representation Method CST, JOURNAL OF AIRCRAFT, vol. 45, no. 1, January-February 2008.

[11]. Ma Dongli, Zhao Yanping, Qiao Yuhang, Li Guanxiong, Effects of relative thickness on aerodynamic charateristics of airfoil at a low Reynolds number, Chinese Journal of Aeronautics, (2015), 28(4): 10031015.

[12]. Ava Shahrokhi, Alireza Jahangirian, Airfoil shape parameterization for optimum Navier-Stokes design with genetic algorithm, Aerospace Science and Technology 11 (2007) 443-450.

[13]. Slawomir Koziela and Leifur Leifssona, Multi-level CFD-based Airfoil Shape Optimization with Automated Low-fidelity Model Selection, International Conference on Computational Science, 18 (2013) 889 - 898.

[14]. Ingen, J.L. van, The $e^{N}$ method for transition prediction. Historical review of work 
at TU Delft, $38^{\text {th }}$ Fluid Dynamics Conference and Exhibit <BR>, Seattle, Washington, June 2008, AIAA 2008-3830.

[15]. Gregory A. Williamson, Bryan D. McGranahan, Benjamin A. Broughton, Robert W. Deters, John B. Brandt, and Michael S. Selig, Summary of Low-Speed Airfoil Data.
[16]. http://www.pointwise.com/gridgen/, Pointwise.

[17]. Ansys Inc, ANSYS FLUENT flow modeling and simulation software.

[18]. http://www.xflr5.com/xflr5.htm, XFLR5 V6.09 